\title{
An Application of Neural Network Technique to Correct the Dome Temperature Effects on Pyrgeometer Measurements
}

\author{
Amauri P. Oliveira And Jacyra Soares \\ Group of Micrometeorology, Department of Atmospheric Sciences, University of São Paulo, São Paulo, Brazil \\ MariJa Z. BožNAR AND PRimož MlaKar \\ AMES d.o.o., Ljubljana, Slovenia \\ JoÃo F. ESCOBEDO \\ Laboratory of Solar Radiation, Department of Environmental Sciences, UNESP, Botucatu, Brazil
}

(Manuscript received 23 February 2005, in final form 20 June 2005)

\begin{abstract}
This work describes an application of a multilayer perceptron neural network technique to correct dome emission effects on longwave atmospheric radiation measurements carried out using an Eppley Precision Infrared Radiometer (PIR) pyrgeometer. It is shown that approximately 7-month-long measurements of dome and case temperatures and meteorological variables available in regular surface stations (global solar radiation, air temperature, and air relative humidity) are enough to train the neural network algorithm and correct the observed longwave radiation for dome temperature effects in surface stations with climates similar to that of the city of São Paulo, Brazil. The network was trained using data from 15 October 2003 to 7 January 2004 and verified using data, not present during the network-training period, from 8 January to 30 April 2004. The longwave radiation values generated by the neural network technique were very similar to the values obtained by Fairall et al., assumed here as the reference approach to correct dome emission effects in PIR pyrgeometers. Compared to the empirical approach the neural network technique is less limited to sensor type and time of day (allows nighttime corrections).
\end{abstract}

\section{Introduction}

The downward longwave radiation fluxes at the surface play an important role in the air-surface interaction. It can be estimated from radiative transfer models (Ellingson et al. 1991; Dutton 1993; Mlawer et al. 1997; Turner et al. 2004), from empirical expressions (Niemelä et al. 2001; Iziomon et al. 2003; Finch and Best 2004), and from observations (Fairall et al. 1998; Philipona et al. 2001; Burns et al. 2003; Marty et al. 2002, Philipona et al. 2004). Despite the good performance, radiative transfer models are difficult to use regularly because they require, for validation, information about the atmospheric thermodynamic state, gas distribution,

Corresponding author address: Amauri Pereira de Oliveira, Departamento de Ciencias Atmosfericas-IAG-USP, Rua do Matao, 126, 05508-900, Sao Paulo, SP, Brazil

E-mail: apdolive@usp.br and radiation measurements at different height levels. Comparatively, empirical expressions are easy to apply but are limited to the conditions of their derivations, and they also require long-term measurements of radiation fluxes, screen temperature, and water vapor pressure to be validated for a particular site and season. Based on these limitations, measuring longwave radiation fluxes using a pyrgeometer is the best option for most of the applications requiring radiation fluxes if the appropriate calibration procedure is performed (Philipona 2001; Reda et al. 2002).

Precision Infrared Radiometer (PIR) pyrgeometers (Eppley Laboratory, Inc.) are the most widely deployed and tested sensors used to measure longwave radiation at the surface (Burns et al. 2003; Marty et al. 2003). According to Fairall et al. (1998), the exclusive use of the manufacturer's instruction can lead to errors in the total flux of up to $5 \%\left(\sim 20 \mathrm{~W} \mathrm{~m}^{-2}\right)$. This error can be a serious problem when the longwave radiation flux is 
used, for instance, to perform energy balances or to recover surface temperatures.

There are different ways to correct pyrgeometer measurements; some of them take into account the heat balance over the thermopile (Philipona et al. 1995; Fairall et al. 1998; Ji and Tsay 2000), while others consider the correlation between the dome heating by solar radiation and the wind ventilation (Pérez and AlladosArboledas 1999). The first option requires simultaneous measurements of dome and case temperatures and information about the calibration factors not provided by the manufacturer (Payne and Anderson 1999).

The empirical approach requires information about wind velocity and solar radiation at the pyrgeometer level, and its application is dome-shape dependent. For instance, Pérez and Allados-Arboledas (1999) developed an expression for a particular pyrgeometer (bulge dome), but it is not obvious that it will work for the others pyrgeometers (flat dome). As far as the authors are concerned, the available empirical expressions have been developed to correct only dome emission due to daytime solar heating and ventilation effects. None have addressed pyrgeometer corrections for nighttime operation.

Here, the neural network technique will be applied to correct the hourly longwave radiation measured using an Eppley PIR pyrgeometer, without simultaneous measurements of case and dome temperatures. It will be assumed that the dome emission effects on the flux are a nonlinear function of other measured meteorological parameters and estimated using multilayer perceptron neural network (MLP) with nonlinear transfer function (Rumelhart et al. 1986; Lawrence 1991).

The neural network (NN) technique has been previously applied to several studies of radiation with hourly resolution, for example, to estimate hourly global solar radiation (Sfetsos and Coonick 2000), global photosynthetic active radiation (López et al. 2001), and, more recently, for diffuse solar radiation (Soares et al. 2004). However, to the knowledge of the authors, the NN technique has never been applied to correct pyrgeometer data. It will be shown here that approximately 7-month-long measurements of longwave radiation flux, dome and case temperatures, global solar radiation, air temperature, and relative humidity are enough to train the neural network algorithm and correct longwave radiation measurements in surface stations with climates similar to that of the city of São Paulo, Brazil.

\section{Meteorological dataset}

Downward longwave atmospheric radiation at surface has been regularly measured in São Paulo City,
Brazil, since September 1997. The measurements are taken on a platform located at the building top of the Instituto de Astronomia, Geofísica e Ciências Atmosféricas da Universidade de São Paulo, at the University Campus, in the western side of São Paulo (744 m MSL; $\left.23^{\circ} 33^{\prime} 35^{\prime \prime} \mathrm{S} ; 46^{\circ} 43^{\prime} 55^{\prime \prime} \mathrm{W}\right)$, with a sampling frequency of $0.2 \mathrm{~Hz}\left(12 \mathrm{~min}^{-1}\right)$ and stored at 5-min intervals. Also measured simultaneously, at the surface level, are (i) global solar radiation, (ii) air temperature, and (iii) relative humidity.

The longwave atmospheric emission has been measured using an Eppley PIR pyrgeometer. This instrument performs hemispherical, broadband, infrared radiative flux measurements, using thermopile temperature difference. Its composite transmission window associated to the silicon dome properties is $4-50 \mu \mathrm{m}$ (Philipona et al. 1995; Ji and Tsay 2000). The PIR pyrgeometer comes with a battery-powered resistance network that provides a voltage that expresses the radiative flux contribution due to the case temperature. Extra channels for measuring case and dome temperatures become available only in October 2003. Prior to 15 October 2003, measurements of longwave radiation with the PIR pyrgeometer followed only the manufacturer recommendations.

A pyranometer model 8-48, also built by Eppley, measured global solar irradiance. This sensor has periodically been calibrated using as secondary standard the Eppley Precision Spectral Pyranometer (PSP). The calibration consists of running, at least once a year, side by side both pyranometers continuously for 2-7 days (Oliveira et al. 2002). A new calibration factor is evaluated by comparing output voltages measured by both pyranometers and using, as reference, the calibration factor of the PSP. During this study the calibration factor for the pyranometer model 8-48 was $8.93 \pm 0.10$ $\mu \mathrm{V} \mathrm{W}^{-1} \mathrm{~m}^{2}$, about $3.4 \%$ larger than the calibration factor provided by the manufacturer in 1991 (8.62 \pm $0.03 \mu \mathrm{V} \mathrm{W} \mathrm{W}^{-1} \mathrm{~m}^{2}$ ).

The air temperature and relative humidity were estimated using a pair of thermistor and capacitive sensors from Vaisala. According to the manufacturer, the air temperature and relative humidity are measured with an accuracy of $0.1^{\circ} \mathrm{C}$ and $2 \%$, respectively, for a range of temperature $0^{\circ}-40^{\circ} \mathrm{C}$ and range of relative humidity $10 \%-90 \%$. The hourly values of wind velocity, used in this work, were measured at the same site during 8 January-30 April 2004 (83 days, or 1992 h) with a cup anemometer from Weather Monitor II, manufactured and distributed by Davis Instruments, Inc. This anemometer has an accuracy of 5\% within 3-34 $\mathrm{m} \mathrm{s}^{-1}$. All data measured at the platform were checked, and questionable data were removed (Oliveira et al. 2002). 
The city of São Paulo is located in the state of São Paulo, Brazil, at approximately $770 \mathrm{~m}$ MSL and $60 \mathrm{~km}$ westward from the Atlantic Ocean. Its climate-typical of subtropical regions of Brazil-is characterized by a dry winter during June-August and a wet summer during December-March. The minimum values of daily monthly averaged temperature and relative humidity occur in July and August $\left(16^{\circ} \mathrm{C}\right.$ and $74 \%$, respectively), and the minimum monthly accumulated precipitation occurs in August (35 mm). The maximum value of daily monthly averaged temperature occurs in February $\left(22.5^{\circ} \mathrm{C}\right)$, and the maximum value of daily monthly averaged relative humidity occurs from December through January and from March through April (80\%). The seasonal distribution of surface wind speed indicated that the São Paulo urban area is characterized by light winds throughout the year, with intensity varying between $0.5 \mathrm{~m} \mathrm{~s}^{-1}$ (January and May) and $1.5 \mathrm{~m} \mathrm{~s}^{-1}$ (September-October), preferentially from the northnortheast direction (Oliveira et al. 2003).

\section{Pyrgeometer measurement corrections}

The atmospheric longwave emission measured by a PIR pyrgeometer can be estimated considering the heat balance given by (Fairall et al. 1998)

$$
\mathrm{LW}_{\text {Fairall }}=\frac{\Delta V}{s_{0}}+\sigma T_{C}^{4}+B \sigma\left(T_{C}^{4}-T_{D}^{4}\right),
$$

where $\mathrm{LW}_{\text {Fairall }}$ is the corrected value of longwave radiation; $\Delta V$ is the thermopile voltage; $\sigma$ is the StefanBoltzmann constant; $T_{C}$ and $T_{D}$ are, respectively, the case and dome temperatures; and $s_{0}$ and $B$ are calibration factors dependent of the sensor direct calibration.

According to Fairall et al. (1998), considering the third term on the right-hand side of expression (1) reduces the error below 5\%. However, expression (1) may not be easily applied, mainly because the manufacturer does not provide the calibration factors, and therefore $s_{0}$ and $B$ have to be estimated indirectly (Payne and Anderson 1999). Besides, as pointed out by Fairall et al. (1998), $T_{C}$ and $T_{D}$ are seldom observed due to the restrictions in the channel numbers of the data acquisition system.

Measurements of longwave radiation with the PIR pyrgeometer following only the manufacturer recommendations that consider a calibration factor, $s_{1}$, applied to the temperature compensate voltage output, $\Delta V_{c}$, are given by

$$
\mathrm{LW}_{\mathrm{Obs}}=\frac{\Delta V_{c}}{s_{1}}=\frac{\Delta V}{s_{0}}+\sigma T_{C}^{4} .
$$

In the case of the pyrgeometer used here (serial number 28594F3), the value of $s_{1}$ provided by the manufacturer is $3.63 \pm 0.04 \mu \mathrm{V} \mathrm{W}^{-1} \mathrm{~m}^{2}$. The longwave radiation measurements, corrected only by manufacturer recommendations, will be hereafter be referred to as observed longwave radiation and indicated by $\mathrm{LW}_{\mathrm{Obs}}$.

The longwave radiation measurements with the additional corrections, as proposed by Fairall et al. (1998), hereafter will be indicated by $\mathrm{LW}_{\text {Fairall }}$ and called corrected longwave radiation. By combining expressions (1) and (2) and using $B=3.5, \mathrm{LW}_{\text {Fairall }}$ was estimated. This value of $B$ was proposed by Fairall et al. (1998) after analyzing several different calibrations of PIR pyrgeometers available in the literature; therefore, this value seems to be the most appropriate to use here.

The error of the PIR pyrgeometer could be reduced further below $3.5 \%$ if $B$ were determined experimentally for each pyrgeometer in conjunction with other calibration factors (Philipona et al. 1995; Ji and Tsay 2000). However, most of the available calibration procedures would require a well-equipped temperature calibration laboratory (Payne and Anerson 1999), which is not available in most of the places, including the site investigated here, that regularly measure atmospheric downward longwave emission.

As previously mentioned, the solar radiation effects on measurements carried out with a PIR pyrgeometer can also be corrected using the empirical expression proposed by Pérez and Allados-Arboledas (1999):

$$
\mathrm{LW}_{\text {Empirical }}=\mathrm{LW}_{\text {Obs }}-[0.033+0.015 \exp (-V / 3.2)] G,
$$

where $V$ is wind speed $\left(\mathrm{m} \mathrm{s}^{-1}\right)$, and $G$ is the corresponding observed values of global solar radiation at the surface $\left(\mathrm{W} \mathrm{m}^{-2}\right)$. The expression (3) was derived originally for direct horizontal solar radiation; however, as pointed out by Pérez and Allados-Arboledas (1999), it can also be applied using global solar radiation. The longwave radiation with the additional correction performed using (3) hereafter will be called empirical longwave radiation and indicated by $\mathrm{LW}_{\text {Empirical }}$.

\section{Neural network technique}

The neural network consists of basic structures called neurons. The neurons only execute summation over weighted input values, passing it to a nonlinear transfer function (tangents, hyperbolic, sigmoid, etc.) to obtain a neuron output value.

The three-layer perceptron artificial neural network with nonlinear transfer function is, in principle, a universal approximator (Hornik et al. 1989) and can be 
represented as a set of nonlinear equations used to calculate the output values from the input values. In the first layer each input parameter has its own neuron. The second layer is a hidden layer represented by several neurons. Each neuron in the second layer receives inputs from all the neuron outputs of the first layer. In the third layer this fully interconnected procedure is repeated again. There, the output layer has one neuron for each output parameter.

Each interconnected layer must have its own weighting factors. The weighting factors are the neural network parameters determined during the training. The structure, the weighting factors, and the nonlinear transfer function give the neural network the ability of a universal approximator (Mlakar and Božnar 1997; Božnar and Mlakar 1998, 2002).

According to Soares et al. (2004), the three-layer perceptron artificial neural network with nonlinear transfer function (Rumelhart et al. 1986; Hornik et al. 1989; Ward Systems Group 1993) is the most effective alternative to more traditional statistical techniques. Unlike other statistical techniques, the MLP makes no prior assumptions concerning the data distribution.

The neural network model consists of the determination of (i) number of layers and number of neurons in each layer (topology), (ii) parameters to be used as input (input features), and (iii) data vectors of input and output pairs (pattern selection) used for training (learning and optimization) and testing.

The training process is basically the determination of the proper interconnection weights based on the learning set patterns so that the neural network output presents the best fit with the output given by the patterns in the optimization dataset. In this way the neural network learns the information given in the learning set but still has the generalizing capabilities, not only memorizing capabilities. The generalizing capabilities ensure that the trained model is able to give reasonable results also for the unknown pattern (during the training period) that differs from (but is still somehow similar to) all training patterns. The generalizing capabilities make the multilayer perceptron neural network a good tool for atmospheric and related problems (Hsieh and Tang 1998; Gardner and Dorling 1998) because the weather is always repeated but never exactly in the same way.

In this work the $\mathrm{NN}$ technique is applied to correct the pyrgeometer data collected without correction of the dome emission effects. In the experiment performed here, the training set (learning and optimization dataset) employs data measured during the period 15 October 2003-7 January 2004, corresponding to 73 days (1752 h).
Each measured or estimated parameter of the database represents a potential MLP input feature, and the corrected downward longwave radiation is the MLP output feature. The database was analyzed, and the most relevant parameters for the MLP construction to be used as neural network input were (i) observed longwave radiation, (ii) global solar radiation, (iii) air temperature, (iv) relative humidity, and (v) local time.

In the experiments performed here, the standard back propagation algorithm was used with learning rate 0.5 and momentum 0.9. Previous works show that this selection of parameters leads to a quick and effective learning (Mlakar and Božnar 1997; Božnar and Mlakar 1998).

The optimization dataset, based on randomly selected $10 \%$ of patterns from the original training set, was used during the training process to periodically test the MLP performance as the "unknown" dataset to determine the MLP's generalization capabilities. The final network was the one that gave the smallest error on the optimization dataset and not on the training set. The testing set used for check the validity of the generated series was taken from 8 January to 30 April 2004, comprising 89 days ( $2136 \mathrm{~h}$ ) of continuous measurements of longwave radiation.

\section{Results}

Figure 1a displays, as an example, the hourly values of longwave radiations observed and corrected using Fairall et al. (1998) during 29 February and 1 March 2004 (yeardays 60 and 61). As expected, the major differences occur when the solar heating is more intense (Figs. 1b,c). The discrepancy between the observed and corrected longwave emission from the atmosphere is superior to $10 \%$ of the daytime observed emission value (Fig. 1b).

During daytime, in general, the dome temperature is considerably greater than the case temperature, indicating an important dome emission (Fig. 2). During nighttime, very often, the dome is slightly warmer than the case, and, as a consequence, the dome emission effects are small but not zero (Fig. 1b).

The resemblance between the longwave value curves obtained from multilayer perceptron neural network output and using the Fairall correction (Fig. 3) indicates that the neural-network-generated data are able to reproduce the corrected longwave measurements.

The scatter diagram between the hourly values of longwave radiations corrected using Fairall et al. (1998) and obtained using the MLP network is displayed in Fig. 4a. The coefficient correlation obtained is $r=0.99$, indicating the good performance of the MLP network. 

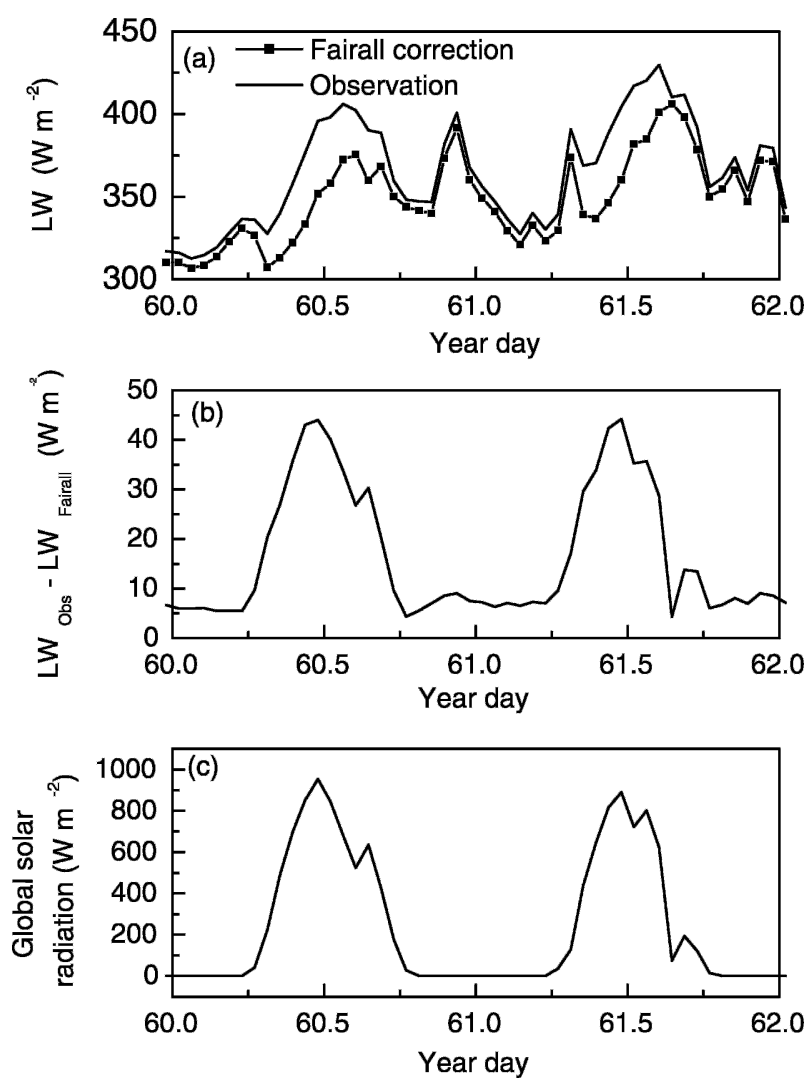

FIG. 1. Diurnal evolution of hourly values of longwave radiation (a) corrected using Fairall et al. (1998) and applying only the manufacturer correction (observed); (b) the difference between them; (c) global solar radiation at the surface. Yeardays 60 and 61 correspond to $29 \mathrm{Feb}$ and 1 Mar 2004.

The longwave radiation difference between that corrected by Fairall et al. (1998) and that using MLP output in Fig. $4 \mathrm{~b}$ also indicates that the MLP performs well in most of the longwave radiation range observed in

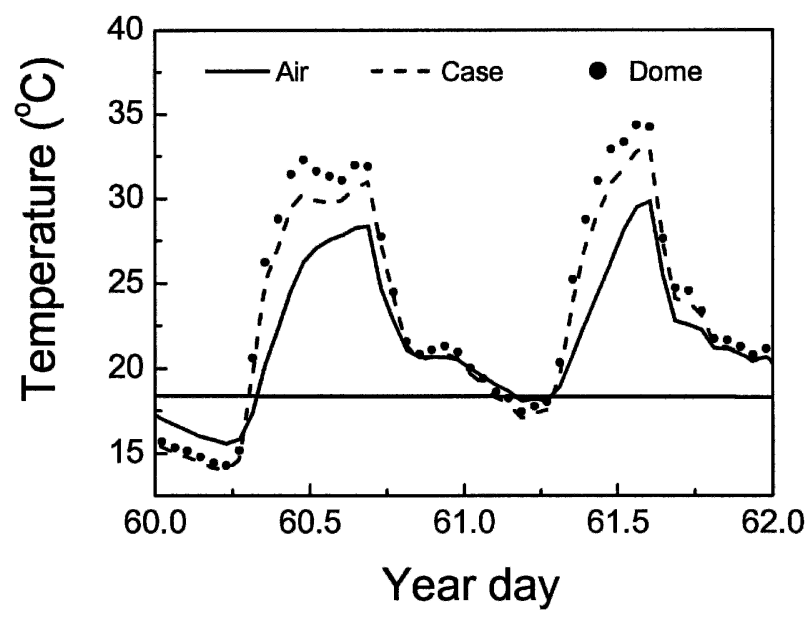

FIG. 2. Diurnal evolution of hourly values of air (line), case (dashes), and dome (dots) temperatures.

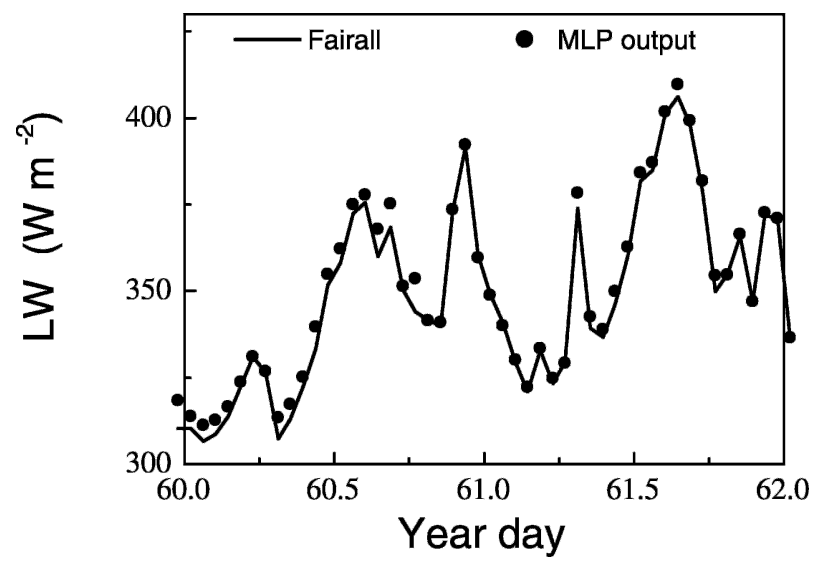

FIG. 3. Hourly values of longwave radiation obtained as MLP neural network output (dots) and using the Fairall et al. (1998) correction (line).

São Paulo during the period of testing (8 January-30 April 2004). The largest mismatch occurs when the longwave radiation values are below $320 \mathrm{~W} \mathrm{~m}^{-2}$. As discussed at the end of this section, this mismatch may be associated with the lack of phenomenological information during the NN training procedure; however, it does not affect significantly the application of $\mathrm{NN}$ in the case of São Paulo.

The histogram of the difference between longwave radiations corrected using Fairall et al. (1998) and obtained using the MLP network is shown in Fig. 5. The standard deviation and the mean error value are also presented in the figure. The mean value is in the vicinity of zero, demonstrating a good performance of the MLP network.

The empirical expression (3) was also applied to estimate the solar heating effect corrections on the measurements of longwave radiation (Fig. 6a). For comparison, the scatter diagrams between the longwave radiation corrections estimated by the Fairall expression (2) and from MLP are indicated in Figs. 6b and 6c. An important characteristic observed from Fig. 6 is that the MLP network (Fig. 6c) follows the dependence with the global solar radiation presented by the Fairall method (Fig. 6b).

The scatter diagram between the longwave radiation corrections obtained empirically, by Fairall, and by MLP shows a similar linear dependence with the global solar radiation (Fig. 6c). The correlation between the correction proposed by Pérez and Allados-Arboledas (1999) and global solar radiation yields a coefficient of -0.99 , which is similar to the Fairall $(-0.98)$ and MLP $(-0.96)$ approaches.

The slope of the linearly fitted curve with the additional corrections proposed by Fairall $(-0.039)$ is similar to the MLP $(-0.037)$ and is not very different from 

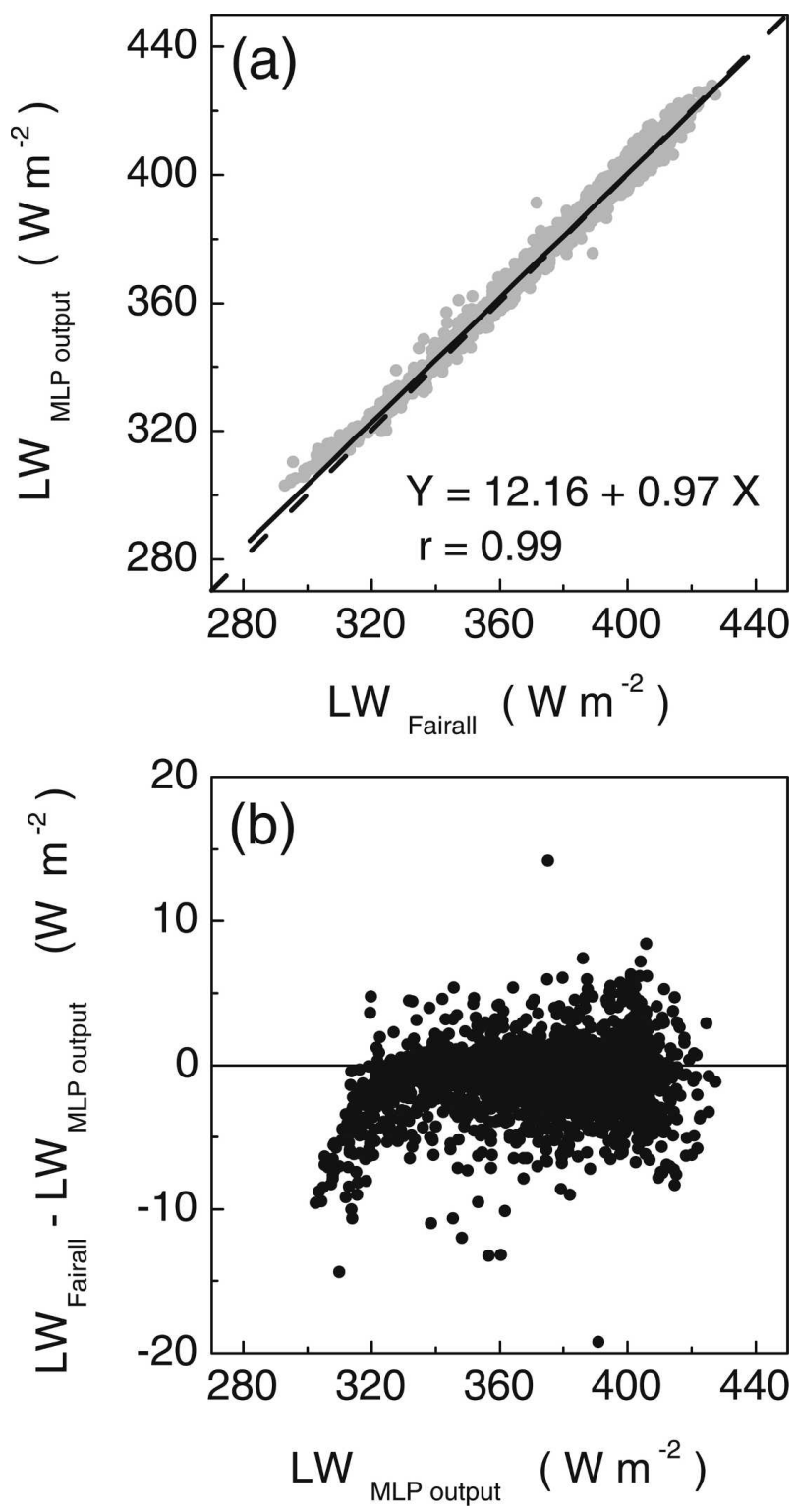

FIG. 4. Scatter diagram between the hourly values of (a) longwave radiation corrected by Fairall et al. (1998) and using MLP output, and (b) longwave radiation difference between that corrected by Fairall et al. (1998) and using MLP output, and that corrected using MLP output. The dashed line in (a) corresponds to the figure diagonal, and the continuous line corresponds to the curve fitted by the least squares method. The corresponding linear equation and the correlation coefficient $(r)$ are also indicated.

the empirical correction $(-0.0 .41)$. However, the intercepts of the linearly fitted curve using the empirical correction $\left(-0.12 \mathrm{~W} \mathrm{~m}^{-2}\right)$, Fairall $\left(-7.73 \mathrm{~W} \mathrm{~m}^{-2}\right)$, and the MLP $\left(-6.43 \mathrm{~W} \mathrm{~m}^{-2}\right)$ are different.

The longwave radiation corrected using Fairall and MLP has a larger point dispersion compared to the empirical expression. During the observational period the winds in São Paulo were very light (Fig. 7), and,

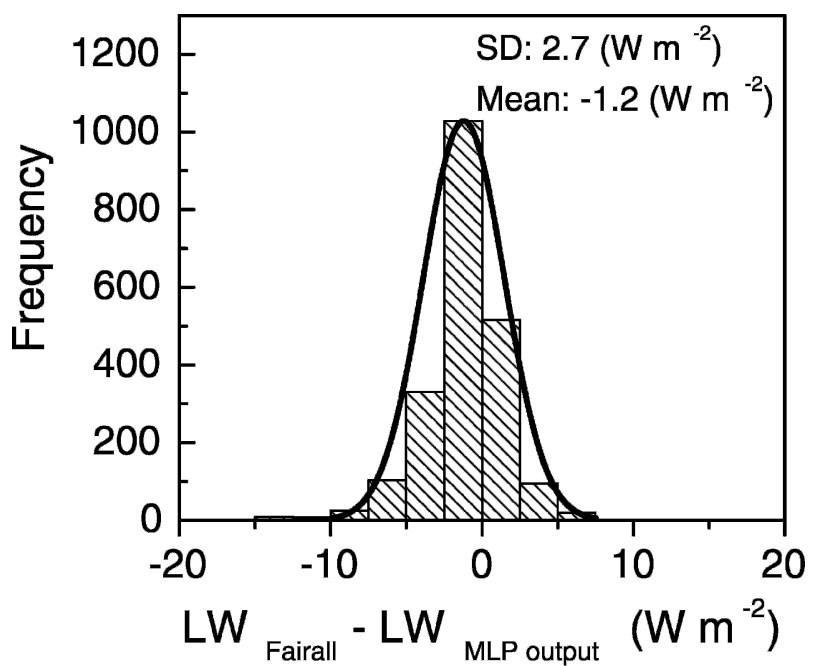

FIG. 5. Histogram of longwave radiation difference between that corrected by Fairall et al. (1998) and that by MLP output, where SD is standard deviation.

therefore, for the case reported here, the ventilation effect was not very important to the empirical correction. This could explain the smaller point dispersion obtained for the empirical approach (Fig. 6a).

The relatively large amount of points present when the global solar radiation values are zero, obtained by Fairall and MLP, are due to nighttime longwave radiation corrections (Fig. 8). In the case of São Paulo, the nighttime corrections seem to be important $(\sim-8 \mathrm{~W}$ $\mathrm{m}^{-2}$ ) and occur with high frequency. This behavior may reflect a local climate condition: wet summer characterized by a convective diurnal cycle, with wind velocities and ventilation very small (Oliveira et al. 2002, 2003). The empirical expressions, like the one used here, cannot account for these corrections.

An important issue concerning neural network applications is the sensitivity of its output to the error in the input. To address this question it is necessary to estimate the measurement error influence on the reproduction, by the MLP, of the corrected longwave radiation values. The NN final error can be quantified comparing the values used in the testing set (not included in the training set) and the MLP output values. Here the difference between the hourly values of the longwave radiation corrected by Fairall et al. (1998), used as testing set, and MLP output can be seen in Figs. 4, 5, and 6. The NN errors can basically be due to the error in the MLP input data (here, the global solar radiation has an error of $1 \%$, air temperature has $0.1^{\circ} \mathrm{C}$ precision, and relative humidity about $5 \%$ ) and due to the pattern and feature selections.

One part of the $\mathrm{NN}$ error is caused by the input data 

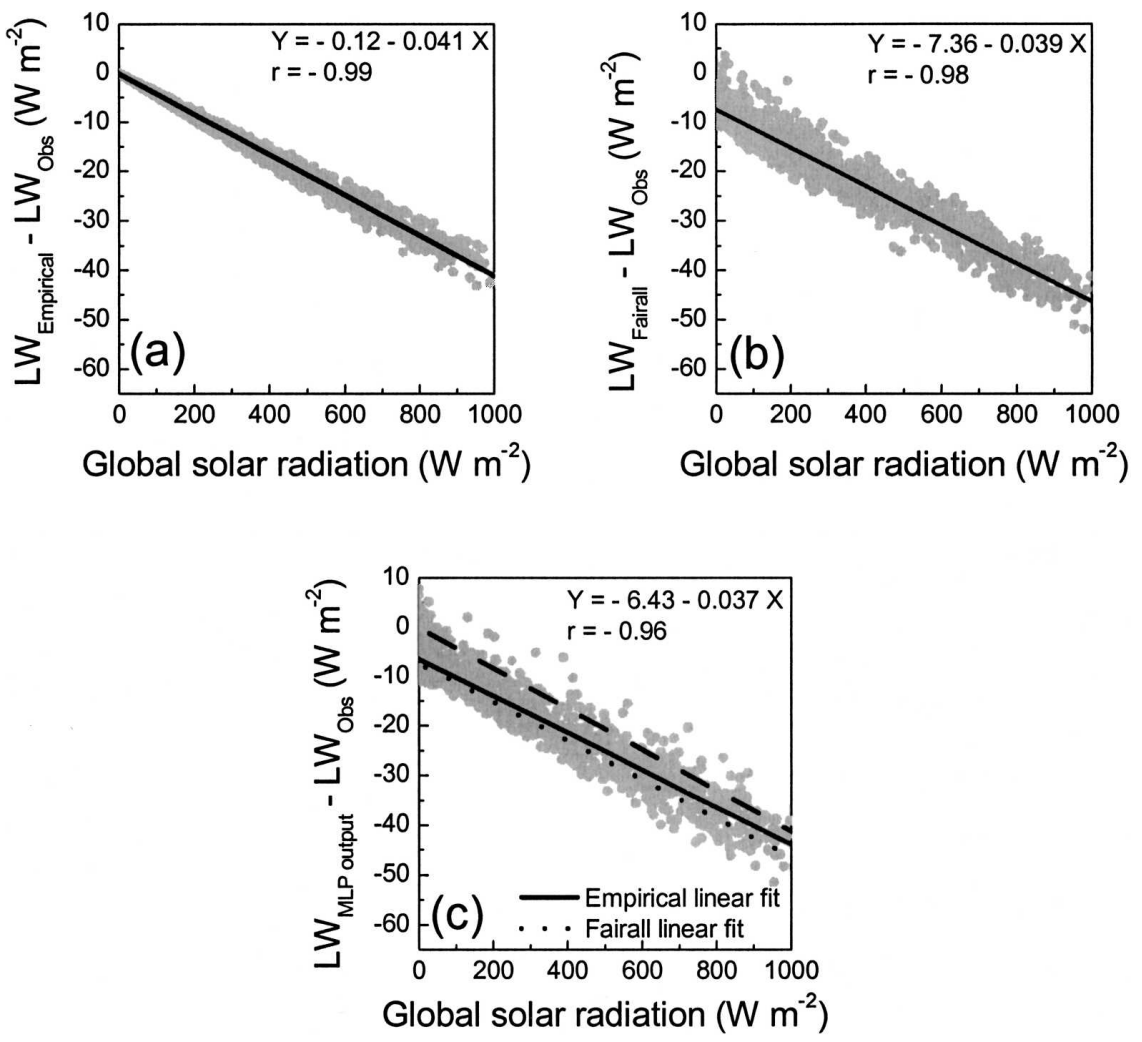

FIG. 6. Scatter diagrams between hourly values of global solar radiation and (a) empiricalobserved longwave radiation difference; (b) Fairall-observed longwave radiation difference, and (c) MLP output-observed longwave radiation difference. Continuous lines correspond to the curve fitted by the least squares method. The corresponding linear equation and the correlation coefficient $(r)$ are also indicated. The dashed and dotted lines in (c) correspond, respectively, to the linear fit obtained in (a) and in (b).

errors that can be treated as having two components: systematic error and white noise added to the actual (unknown) value of the input parameter. The $\mathrm{NN}$ will not be affected by the systematic part of the error when the MLP training dataset consists of patterns obtained independent of the MLP output because the NN can detect a systematic shifted relationship between inputs and outputs. However, white noise components can spread through the neural network until it influences the output and can be responsible for one part of the error obtained here (Helmut 1991). Here, the training was composed by longwave radiation values corrected directly from measurements using Fairall et al. (1998), and therefore the MLP output should not be affected by the systematic and white noise errors other than those inferred by the error propagation analysis carried out by Fairall et al. (1998, their section 4).

The other source of NN error is the lack of phenomenological information. To minimize this type of error it is necessary to perform appropriate pattern and feature selections. Usually, when the number of input pa- rameters is large and the relationship among them is not known the feature selection is performed, training the model with all available inputs and then choosing the inputs that have a significant contribution factor (Soares et al. 2004). The contribution factor of a particular parameter is the sum of the absolute weights guiding from the correspondent input neuron to the neurons in the hidden layer. The highest scores indicate the most relevant parameters to be feature inputs for the final network. This method gives the same results as the heuristic selection based on the theoretical knowledge of the phenomenon (Mlakar and Božnar 1997).

In the case presented here, the feature selection procedure was considerably shortened because the input parameters were intentionally limited to those commonly available in a regular surface station. Therefore, instead of contribution factor analysis, the most relevant inputs were selected by trial-and-error analysis of the NN performance, considering as criteria the linear correlation coefficient between longwave radiation corrected by Fairall et al. (1998) and using MLP output. 


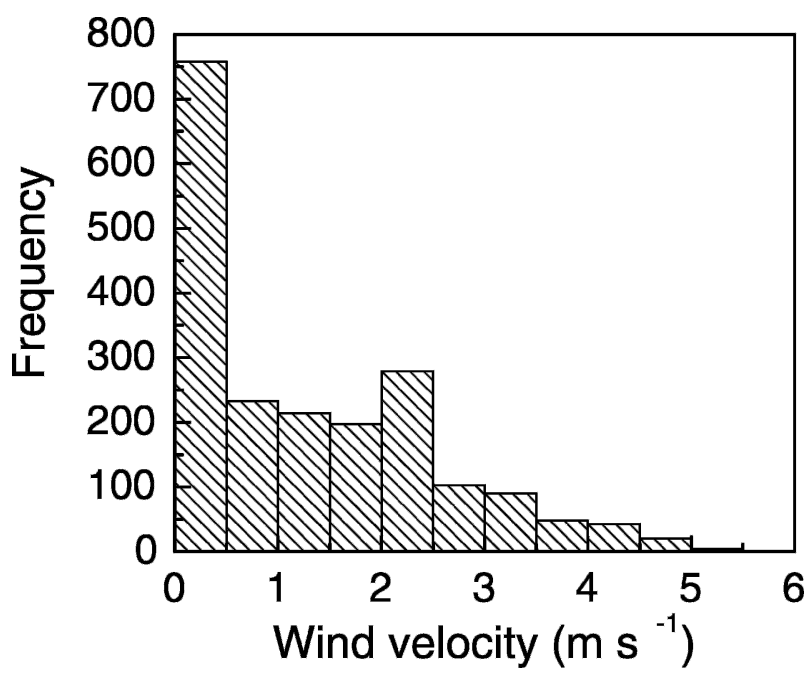

FIG. 7. Histogram of wind speed.

This analysis was performed using the entire dataset $(8$ January-30 April 2004) and indicated that the best correlation (correlation coefficient $=0.996$ ) was obtained when the $\mathrm{NN}$ was used with the following inputs: (i) observed longwave radiation, (ii) global solar radiation, (iii) air temperature, (iv) relative humidity, and (v) local time.

In this study, the pattern selection was carried out using the entire dataset available with simultaneous longwave radiation data corrected by Fairall et al. (1998). The dataset, from 15 October 2003 to 30 April 2004, covers part of the spring, entire summer, and a fraction of fall seasons of the studied site. However, the longwave radiation corrected by the MLP does not seem to be significantly affected by the possible neglected winter typical patterns. During winter, the cli- mate in the São Paulo region is not appreciably different from the summer period with regard to temperature, solar radiation, and wind velocity (Oliveira et al. 2002, 2003). Therefore, dome emission values caused by daytime solar heating or nighttime cooling between October and April, in São Paulo, are likely to be representative of dome emission effects also during the winter period.

The hourly monthly average diurnal evolution of the longwave radiation atmospheric downward emission measured at the surface with the PIR pyrgeometer without Fairall correction indicates that, on average, the LW values were systematically higher than $320 \mathrm{~W}$ $\mathrm{m}^{-2}$ (Fig. 9). According to Fig. 4, $320 \mathrm{~W} \mathrm{~m}^{-2}$ is the lower limit value of the LW range where the MLP has a good performance. This result corroborates the hypothesis that the pattern selection was enough to account for the dome emission effects. However, sites with more seasonal climate variability should use, at least, $1 \mathrm{yr}$ of data for training set selection in order to cover all reasonable weather conditions.

\section{Discussion and conclusions}

This paper presents a methodology for generating synthetic series of longwave radiation, corrected for dome emission effects on an Eppley PIR pyrgeometer, based on neural network called multilayer perceptron. The motivation here is to use the neural network to remove dome emission effects on pyrgeometer measurements carried out without dome and case temperature measurements. This is particularly relevant at the investigated site where dome and case temperatures started to be measured only in October of 2003, about $6 \mathrm{yr}$ after starting to measure longwave downward atmospheric emission, in September 1997.
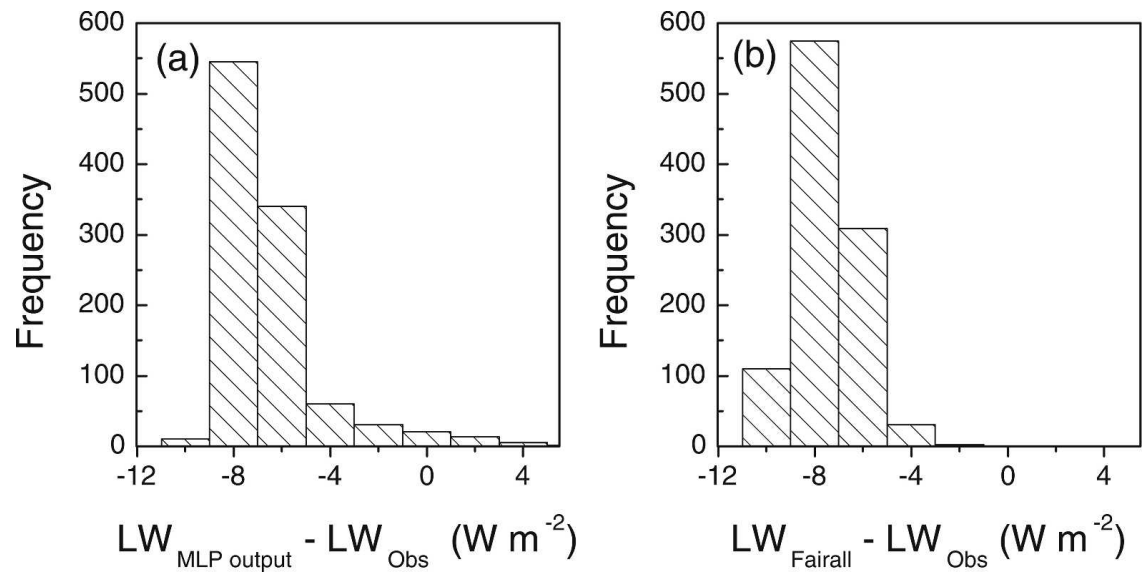

FIG. 8. Histogram of (a) Fairall-observed longwave radiation difference and (b) MLP output-observed longwave radiation difference, for nighttime. 


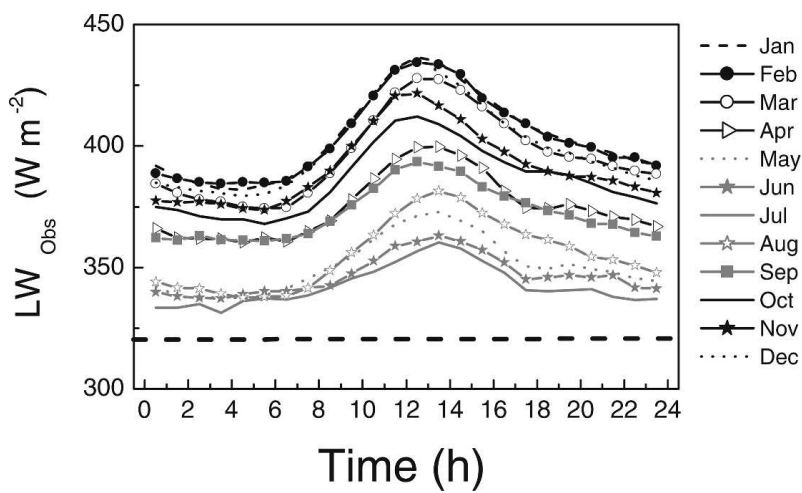

FIG. 9. Time evolution of the hourly monthly average longwave atmospheric downward emission measured at the surface using the PIR pyrgeometer in São Paulo, during 1 Sep 1997-30 Apr 2004. The horizontal dashed line is the threshold of $320 \mathrm{~W} \mathrm{~m}^{-2}$. No correction was applied.

The MLP methodology is based on the possibility of implicitly employing information associated with the problem without knowing the existing relationships between different variables and sources of information. To apply the MLP parameters developed herein, it is necessary to have only accessible meteorological parameters (global solar radiation, air temperature, and relative humidity) simultaneously to atmospheric longwave radiation measurements corrected only by manufacturer recommendations.

The longwave radiation values generated by the MLP were very similar to the Fairall (1998) values, assumed here as the reference approach to correct dome emission effects in PIR pyrgeometers. The good performance of the MLP neutral network indicates that the temperature effect on downward longwave atmospheric radiation, measured at the surface with an Eppley pyrgeometer, can be corrected using only about 7-month-long measurements of dome and case temperatures, global solar radiation, air temperature, and air relative humidity at surface stations with similar climates to São Paulo City.

Compared to the empirical approach, the MLP methodology is less limited to a particular place, sensor, and time of day. The MLP approach also has the advantage of allowing nighttime corrections of longwave radiation measurements. The nighttime correction seems to be important $\left(\sim-8 \mathrm{~W} \mathrm{~m}^{-2}\right)$ in places with low wind velocity, like São Paulo.

The methodology of the MLP neural network described here can be used for other places, and also for other sensors, as a general approach to improve the quality of the existing data by including corrections based on the technological improvement observed in the last years or even on removing systematic errors caused by sensor malfunctioning. Special care has to be taken concerning the procedure of pattern and feature selection.

Acknowledgments. This research was sponsored by Conselho Nacional de Desenvolvimento Científico e Tecnológico (CNPq) during the Brazil-Slovenia collaboration program (Proc. CNPq 490017/02-9). On the Slovenian side the research was sponsored by the AMES Company and Slovenian Ministry for School, Science and Sport during the same collaboration program. We are grateful to Dr. Ricardo de Camargo for providing the wind data and Antonio J. Machado for the assistance during this research.

\section{REFERENCES}

Božnar, M., and P. Mlakar, 1998: Improvement of air pollution forecasting models using feature determination and pattern selection strategies. Air Pollution Modeling and Its Application XII, S.-E. Gryning and N. Chaumerliac, Eds., Plenum Press, 725-726.

—, and — 2002: Use of neural networks in the field of air pollution modeling. Air Pollution Modeling and Its Application $X V$, C. Borrego and G. Schayes, Eds., Kluwer Academic, 375-383.

Burns, S. P., J. Sun, A. C. Delany, S. R. Semmer, S. P. Oncley, and T. W. Horst, 2003: A field intercomparison technique to improve the relative accuracy of longwave radiation measurements and an evaluation of CASES-99 pyrgeometer data quality. J. Atmos. Oceanic Technol., 20, 348-361.

Dutton, E. G., 1993: An extended comparison between LOWTRAN7 computed and observed broadband thermal irradiances: Global extreme and intermediate surface conditions. J. Atmos. Oceanic Technol., 10, 326-336.

Ellingson, R. G., J. Ellis, and S. Fels, 1991: Intercomparison of radiation codes used to climate models: Long wave results. $J$. Geophys. Res., 96, 8929-8963.

Fairall, C. W., P. O. G. Persson, E. F. Bradley, R. E. Payne, and S. P. Anderson, 1998: A new look at calibration and use of Eppley precision infrared radiometers. Part I: Theory and application. J. Atmos. Oceanic Technol., 15, 1229-1242.

Finch, J. W., and M. J. Best, 2004: The accuracy of downward short- and long-wave radiation at the earth's surface calculated using simple models. Meteor. Appl., 11, 33-39.

Gardner, M. W., and S. R. Dorling, 1998: Artificial neural networks (the multiplayer perceptron) - A review of applications in the atmospheric sciences. Atmos. Environ., 32, 2627 2636.

Helmut, L., 1991: Introduction to Multiple Time Series Analysis. Springer-Verlag, $545 \mathrm{pp}$.

Hornik, K., M. Stinchcombe, and H. White, 1989: Multi-layer feedforward networks are universal approximators. Neural Networks, 2, 359-366.

Hsieh, W. W., and B. Tang, 1998: Applying neural network models to prediction and data analysis in meteorology and oceanography. Bull. Amer. Meteor. Soc., 79, 1855-1870.

Iziomon, M. G., H. Mayer, and A. Matzarakis, 2003: Downward atmospheric longwave radiation under clear and cloudy skies: 
Measurement and parameterization. J. Atmos. Solar-Terr. Phys., 65, 1107-1116.

Ji, Q., and S.-C. Tsay, 2000: On the dome effect of Eppley pyrgeometers and pyranometers. Geophys. Res. Lett., 27, 971974.

Lawrence, J., 1991: Data preparation for a neural network. Artif. Intell. Expert, 6 (11), 34-41.

López, G., M. A. Rubio, M. Martinez, and F. J. Batlles, 2001: Estimation of hourly global photosynthetically active radiation using artificial neural network models. Agric. For. Meteor., 107, 279-291.

Marty, C., R. Philipona, C. Fröhlich, and A. Ohmura, 2002: Altitude dependence of surface radiation fluxes and cloud forcing in the Alps: Results from the Alpine surface radiation budget network. Theor. Appl. Climatol., 72, 137-155.

— certainty under artic atmospheres: Measurements and modeling. J. Geophys. Res., 108, 4358, doi:10.1029/2002JD002937.

Mlakar, P., and M. Božnar, 1997: Perceptron neural networkbased model predicts air pollution. Proc. Conf. on Intelligent Information Systems (IIS'97), Grand Bahama Island, Bahamas, IEEE Computer Society, 345-349.

Mlawer, E. J., S. J. Taubman, P. D. Brown, M. J. Iacono, and S. A. Clough, 1997: Radiative transfer for inhomogeneous atmospheres: RRTM, a validated correlated-k model for the longwave. J. Geophys. Res., 102, $16663-16682$.

Niemelä, S., P. Räisänem, and H. Savijärvi, 2001: Comparison of surface radiative flux parameterizations. Part I: Longwave radiation. Atmos. Res., 58, 1-18.

Oliveira, A. P., J. F. Escobedo, A. J. Machado, and J. Soares, 2002: Diurnal evolution of solar radiation at the surface in the city of São Paulo: Seasonal variation and modeling. Theor. Appl. Climatol., 71, 231-249.

_ - R. Bornstein, and J. Soares, 2003: Annual and diurnal wind patterns in the city of São Paulo. Water, Air Soil Pollut.: FOCUS, 3, 3-15.

Payne, R. E., and S. P. Anderson, 1999: A new look at calibration and use of Eppley precision infrared radiometers. Part II: Calibration and use of the Woods Hole Oceanographic In- stitution improved meteorology precision infrared radiometer. J. Atmos. Oceanic Technol., 16, 739-751.

Pérez, M., and L. Allados-Arboledas, 1999: Effects of natural ventilation and solar radiation on the performance of pyrgeometers. J. Atmos. Oceanic Technol., 16, 174-180.

Philipona, R., 2001: Sky-scanning radiometer for absolute measurements of atmospheric long-wave radiation. Appl. Opt., 40, 2376-2383.

— C. Fröhlich, and Ch. Betz, 1995: Characterization of pyrgeometers and the accuracy of atmospheric long-wave radiation measurements. Appl. Opt., 34, 1598-1605.

- , and Coauthors, 2001: Atmospheric longwave irradiance uncertainty: Pyrgeometers compared to an absolute skyscanning radiometer, atmospheric emitted radiance interferometer, and radiative transfer model calculations. J. Geophys. Res., 106 (D22), 28 129-28 141.

_ B. Dürr, and C. Marty, 2004: Greenhouse effect and altitude gradients over the Alps-By surface longwave radiation measurements and model calculated LOR. Theor. Appl. Climatol., 77, 1-7.

Reda, I., J. R. Hickey, T. Stoffel, and D. Myers, 2002: Pyrgeometer calibration at the National Renewable Energy Laboratory (NREL). J. Atmos. Solar-Terr. Phys., 64, 1623-1629.

Rumelhart, D. E., G. E. Hilton, and R. J. Williams, 1986: Learning internal representation by error propagation. Parallel Distributed Processing: Explorations in the Microstructure of Cognition, D. E. Rumelhart and J. L. McClelland, Eds., Vol. 1, MIT Press, 547 pp.

Sfetsos, A., and A. H. Coonick, 2000: Univariate and multivariate forecasting of hourly solar radiation with artificial intelligence techniques. Solar Energy, 68, 169-178.

Soares, J., A. P. Oliveira, M. Z. Božnar, P. Mlakar, J. F. Escobedo, and A. J. Machado, 2004: Modeling hourly diffuse solar-radiation in the city of São Paulo using a neuralnetwork technique. Appl. Energy, 79, 201-214.

Turner, D. D., and Coauthors, 2004: The QME AERI LBLRTM: A closure experiment for downwelling high spectral resolution infrared radiance. J. Atmos. Sci., 61, 2657-2675.

Ward Systems Group, 1993: Neuroshell 2 user's manual. Ward Systems Group, Inc., 254 pp. 